\title{
Mobile Service Affordability for the Needy, Addiction, and ICT Policy Implications
}

\author{
L-F Pau
}

\begin{tabular}{|l|l|}
\hline \multicolumn{2}{|l|}{ ERIM REPORT SERIES RESEARCH IN MANAGEMENT } \\
\hline ERIM Report Series reference number & ERS-2008-023-LIS \\
\hline Publication & April 2008 \\
\hline Number of pages & 9 \\
\hline Persistent paper URL & http://hdl.handle.net/1765/12246 \\
\hline Email address corresponding author & Ipau@rsm.nl \\
\hline Address & Erasmus Research Institute of Management (ERIM) \\
& RSM Erasmus University / Erasmus School of Economics \\
& Erasmus Universiteit Rotterdam \\
& P.O.Box 1738 \\
& 3000 DR Rotterdam, The Netherlands \\
& Phone: + 31 10 408 1182 \\
& Fax: + 31104089640 \\
& Email: info@erim.eur.nl \\
& Internet: www.erim.eur.nl \\
\hline
\end{tabular}

Bibliographic data and classifications of all the ERIM reports are also available on the ERIM website: www.erim.eur.nl 


\section{ERASMUS RESEARCH INSTITUTE OF MANAGEMENT}

\section{REPORT SERIES}

\section{RESEARCH IN MANAGEMENT}

\begin{tabular}{|c|c|}
\hline \multicolumn{2}{|c|}{ ABSTRACT AND KEYWORDS } \\
\hline Abstract & $\begin{array}{l}\text { This paper links communications and media usage to social and household economics } \\
\text { boundaries. It highlights that in present day society, communications and media are a necessity, } \\
\text { but not always affordable, and that they furthermore open up for addictive behaviours which } \\
\text { raise additional financial and social risks. A simple and efficient methodology compatible with } \\
\text { state-of-the-art social and communications business statistics is developed, which produces the } \\
\text { residual communications and media affordability budget and ultimately the value-at-risk in terms } \\
\text { of usage and tariffs. Sensitivity analysis provides precious information on communications and } \\
\text { media adoption on the basis of affordability. Case data are surveyed from various countries. ICT } \\
\text { policy recommendations are made to support widespread and responsible communications } \\
\text { access. }\end{array}$ \\
\hline Free Keywords & mobile service, communications affordability, ICT policy, addiction \\
\hline Availability & $\begin{array}{l}\text { The ERIM Report Series is distributed through the following platforms: } \\
\text { Academic Repository at Erasmus University (DEAR), DEAR ERIM Series Portal } \\
\text { Social Science Research Network (SSRN), SSRN ERIM Series Webpage } \\
\text { Research Papers in Economics (REPEC), REPEC ERIM Series Webpage }\end{array}$ \\
\hline Classifications & $\begin{array}{l}\text { The electronic versions of the papers in the ERIM report Series contain bibliographic metadata } \\
\text { by the following classification systems: } \\
\text { Library of Congress Classification, (LCC) LCC Webpage } \\
\text { Journal of Economic Literature, (JEL), JEL Webpage } \\
\text { ACM Computing Classification System CCS Webpage } \\
\text { Inspec Classification scheme (ICS), ICS Webpage }\end{array}$ \\
\hline
\end{tabular}




\title{
Mobile service Affordability for the Needy, Addiction, and ICT policy implications
}

\author{
L-F Pau \\ Prof. Mobile business, Rotterdam school of management and Copenhagen Business School \\ lfp.inf@cbs.dk; lpau@rsm.nl
}

\begin{abstract}
This paper links communications and media usage to social and household economics boundaries. It highlights that in present day society, communications and media are a necessity, but not always affordable, and that they furthermore open up for addictive behaviours which raise additional financial and social risks. A simple and efficient methodology compatible with state-of-the-art social and communications business statistics is developed, which produces the residual communications and media affordability budget and ultimately the value-at-risk in terms of usage and tariffs. Sensitivity analysis provides precious information on communications and media adoption on the basis of affordability. Case data are surveyed from various countries .ICT policy recommendations are made to support widespread and responsible communications access.
\end{abstract}

\section{Introduction}

In classical economics, very often the costs of communications and media services are just treated as a consumable, not realizing their social and business roles as opposed to a consumption to achieve survival or production for households or enterprises. As a result the costs of these services is included into either the cost of living index via a nominal percentage and tariff, or as a nominal share in the general and administration expenses of corporations. But not much work has been devoted to the evolution and the forces driving the changes in these nominal shares .

Over the past 20 years, running in parallel with the deregulation of communications and media suppliers, as well as with the widespread development of e-business, but above all to the individualism and social identity drives $[1,2]$, the traffic volumes and expenses devoted by households and companies alike to such services has grown tremendously .

Actually, looking at the share of the total costs of communications and media services to household disposable income (after taxes), as well as for corporations to the equivalent ratio to general and administration expenses (assumed to be budgetized), it is found to be in a range of 15-30\% comparable to equally critical items such as housing costs for households or facilities costs to corporations [3, 4]!

As trade-offs are bound to take place both in phases of growth as well as reduction in income, one essential question is the relative elasticity of demand for communications and media vs. such other equally important expense items. In general terms there are limits in terms of affordability of such communications and media expenses.

Pushing the issue further to the individual level in a household, but also to company priorities has been observed recently an alarming growth of addictive behaviours by both. Some youngsters but also some types of adults prefer to spend more on especially mobile and Internet content services than on say food, sports or other forms for health care .Likewise, some small entrepreneurs but also some types of corporate functions (e.g. in sales or support), have shifted to more expensive wireless communications due to their ubiquity, and end up beefing up overhead expenses linked to their communications preferences, at the expense of the value-added generated not to talk about short term direct personnel costs to the corporation.

This leads to a set of research questions of importance to different stakeholders.

-What are the typical risk implications from addictive communications and media consumption behaviours? This affects in the extreme situations consumer credit and/or insolvency for individuals, but also cash flow and returns on sales for corporations. 
-Which best practices should and can communications and media service suppliers adopt to pre-empt such addictive behaviours? In terms of ICT platforms, such as OSS and billing platforms, what are the consequences?

-What are the pre-emptive educational, policy and counselling measures by public authorities and suppliers alike?

The paper starts by analyzing affordability for communications and media services, especially for households. It then proposes residual income as an analytical tool, to which risk methodologies such as value at risk can be applied. Simple and efficient methodologies, leading to an analysis tool, have been developed and tit is shown how sensitivity analysis yields precious information for communications and media adoption on the basis of affordability. The research questions are then dealt with.

For lack of space only a few summary results are given for specific geographical areas .For obvious reasons, credit is given to much more established work on housing affordability. Compliant with traditions in microeconomic data collection and in line with UN Statistics, the unit of population is the household, the size of which is dependent on demographic, social, and other aspects. The assumption made on that basis is that the members of one household share the communications and media accesses; if not, simple correction factors can be applied.

\section{Affordability of communications and media}

What is affordability of communications and media services? Most fundamentally, it is an expression of the social and material experiences of people, constituted as households or enterprises, in relation to their individual situations .Affordability expresses the challenge each household or enterprise faces in balancing the cost of its actual or potential communications and media cost, on one hand, and the other imposed expenditures, on the other, within the constraints of their income.

However, public policy and the interpretation of individual experiences are mediated through analytical indicators and normative standards of communications and media usage that transcend individual experiences .Such indicators and standards make it possible to arrive at conclusions, potentially contentious to be sure, about the overall extent of affordability and needs, as well as their distribution socially and geographically.

Whereas housing affordability is governed by rule of thumb indicators to determine eligibility and payment levels (typically $30 \%$ in Europe and USA representing housing costs to net income), communications and media affordability indicators do not exist to help suppliers categorize subscribers (pre-or post paid) .

Paralleling substantive issues relating to housing affordability, it is proposed to identify the following tensions related to communications and media affordability:

a. conceptual rigor vs. practical policy implications : communications policies such a universal service provisioning are inevitably shaped by factors other than the conceptual clarity of the affordability standard ,such as potentially perverse incentives, social and health risks, fiscal constraints (to wireless or Internet coverage) ,etc.. In $[5,6,7,8]$ e.g. have given considerable attention to affordability measures, yet ultimately have been unable to extricate themselves from this tangle.

b. communications and media affordability vs. "affordable service consumption": Many suppliers by content quality, transmission / distribution technologies and by quality-of-service measures often try to differentiate abundant and high quality services, and to tailor bundles into affordable bundles for user categories. But affordability is not a characteristic of communications and media services, it is a relationship between these services and people (private or business people) .For some people, all communications and media is affordable, no matter how expensive; for others, no communications, or media are affordable unless they are free." Affordable" communications and media services can have a meaning (and utility) only if three essential questions are answered: (1) affordable to whom? (2) on what standard of affordability? (3) for how long? No academic research discusses "affordable communications and media services", and anyway precise and consistent definitions would be hard to craft. A more relevant ,but not discussed, notion would be "below-industry standards" communications and media services , such as GSM voice-only services, ISDN or under $128 \mathrm{~kb}$ IP connections, analogue television, etc ... These would be identifiable services and service attributes usually offered at low rates, without making any unjustifiable claim of affordability .

c. communications and media affordability vs. quality standards in communications and media: deprivation or denial of communication and media services can take a variety of forms of which affordability is only one. Users may use communications and media paid by others for private purposes, may have insecure / 
shared / non permanent connections, may have low or overcrowded coverage, cannot handle the user interfaces, or to move far to access communications and media. While each of these and other forms of deprivation is logically distinct from lack of affordability ,most households and companies that experience one or more of these forms of deprivation in reality do so because they cannot afford satisfactory access to communications and media. Then, how should account for those households and companies that seem not to have an affordability problem (as measured by some standard), yet do experience one or another form of service deprivation? While communications and media deprivation is complex and can take various forms, standards for most forms of deprivation (except connectivity and coverage) are not well established .Furthermore; could it not be argued that those households might not have an affordability problem if they were over-provisioned? The difficulty of course arises again from the question of what is a broadly acceptable operational definition of a reasonable service and capability provisioning. Another question of greater subtlety is, whether households or companies are considered over-provisioned if they have bandwidth for anticipated services such as Mobile TV, TVOIP, etc? Thus, the number of households that appear to have an affordability problem ,but would not have it if they were over-provisioned, is likely to be considerably lower based on some flexible standard rather than a simplistic bandwidth/ person or content- Mbytes/person definitions of what it means to be over-provisioned .In sum, communications and media affordability is not really separable from the corresponding standards ; because of this, such affordability studies should ideally be iterative : applying economic affordability standards in the first instance, while exploring ways of enhancing of enhancing the precision of the analysis of the analysis later to account for under-or over-provisioning .In [9] have been developed and applied such quality based measures, which classify a household as having an affordability problem not on the basis of actual service costs in relation to income, but on what it would cost to obtain services of a basic provisioning quality standard within a given market

d. a normative standard of affordability vs. empirical analysis of communications and media costs in relation to incomes: studies of consumer expenditures have been carried out for a long time yielding information on how households have spent their items, but they have not dealt with communications and media expenditures. In [5] has explicitly been distinguished between an indicator which measures empirically the relationship between say communications and media costs and incomes, and a standard, which specifies normatively the appropriate values that an indicator should take or not exceed. In reality what most households pay for communications and media is not what they realistically can "afford": many addicted individuals pay much more, some pay less, whether measured in money or as a percentage of income.

As a result, measures of affordability of communications and media can be defined:

-in relative terms, say e.g. vs. cost of living [10];

-in subjective terms, whatever individual households are willing to or choose to spend, while realizing that the degree of financial flexibility increases with income [11];

-vs. family or individual's budget: monetary standards based on an aggregate expenditure patterns [12, 13, 14]; -as a ratio, say of maximum acceptable communications and media costs / income;

-as a residual, as normative standards of a minimum income required to meet other household needs (such as food, health, education and housing) at a basic level after paying for communications and media $[23,30]$.

Largely because of the diversity in service definitions, in bundles, in access technologies, and in quality of service, most approaches except the last are flawed in a way or another. The residual income approach fits well the information society concepts because it arises from the recognition that because of communications and media's distinctive information attributes in comparison with necessities, its cost makes one of the largest and least flexible claims (together with housing, and health in some regions of the world) on after-tax income for most households .In other words, non communications (and housing /health) expenditures are limited by how much is left after paying for communications, media, housing and possibly health ( in the absence of extensive health insurance schemes).This means that a household has a communications and media affordability problem if it cannot meet its non communications needs at some basic level of adequacy after paying for communications, media and housing .Generalizing from household economies of scale effects, tells us that since the non communications expenses of small households are on average less than those of large households, the former can reasonably devote a higher percentage of income to communications and media than larger households with the same income .In this way, the residual income standard emerges as a sliding scale of communications and media affordability with the maximum 
affordable amount and fraction of income varying with household size, type, location (due to cost of living) and income.

In the USA, the lower standard budgets (for two adults and two children) analyzed by the Economic Policy Institute (EPI) [12], and the Wider Opportunities for Women group [15] for 2003 in Boston were 25690 USD 30132 USD/Year depending on the study group, compared to a US Poverty threshold of 18660 USD $([15,16]$.But the communications and media share is amalgamated inside "Other goods and services" with amounts of 42005594 USD /Year, or to 13-18 \% .In Denmark for 2003, the equivalent lower standard budget was 150600 DKK [17] and the "Other goods and services "share was $15 \%$.In France, for 2005 according to NGO Secours catholique [18] the national poverty threshold was 817 Euros/Month and the NGO had interventions of which at least $84 \%$ were under that threshold, and communications and media represented 22 Euros / month in average (lower for fixed access, and higher for wireless access) .

\section{Addiction to communications and media}

Addiction is the psychological and social behavior in which individuals loose any restraint to consumption of a good or service .The addiction process is usually gradual with strong up's and down's , and, as far as communications and media are concerned can end up being only limited by natural necessities such as sleep .It affects individuals in all classes of society and almost all age groups, with young people, singles and individual adults isolated alone day-time being especially affected. While in the past speech and viewing the village center were "free", communications and media addiction hits earlier due to affordability limitations as discussed in the previous Section .. Such addictive behaviors, e.g. with mobile phones, lead to a change in the social sphere of the individuals [19]. To meet their payment obligations, while satisfying their addictive dispositions, the exposed individuals very often cut on necessities and, when possible, use consumer lending. From the risk theory point of view, building on the assertions of Kahneman and Tversky, in a situation of known customer addiction, where the credit institution and/or communications operator will recognize they are exposed to a loss, they will adopt a randomizing policy based on value at risk.

One consequence is high endebtness due to life style addiction to communications and media. According to Intrium Justitia Switzerland (with its 2,5 Million/year credit reports data base) (Intrium Justitia [20]), the typical Swiss indebted individual lives in a town ,alone, is aged 25-34 years ,has little institutional training or is an individual entrepreneur. The debt risk indicator for the 25-34 years age group is $61 \%$ higher than the national average, while the over 65 year old seniors have indicators $49 \%$ lower , and the rural inhabitants stay close to the average. An essential finding is that current penetration rate of mobile service subscriptions (post-or pre-paid) in the same age group is close to $92 \%$, and that the post paid rate is only $16 \%$, which is indicative of a high share of running pre-paid subscriptions having the same high credit risk exposure profile as other budget items. Internet and Blackberry addiction are reported daily by [21] .Mobile phone addiction is common in many markets including Asia [22].

In the United Kingdom, according to survey company YouGov in April 2007 , 1.7 Million individuals have difficulties paying back their debt, 1 Million are close to or in personal insolvency, and Intrium Justitia [20] has established an average credit loss rate of $1,8 \%$, and three times more on recoverable debts to communications suppliers .In Sweden, one third of the consumers in the age group 15-25 years gets costly payment reminders, often from communications and media suppliers. The 25 country wide European payment index of Intrium Justitia is published annually on www.europayment.com.

\section{Methodology}

In view of the importance of the related affordability and communications and media addiction issues, it is first recommended to collect by household, size, region, income level, using the residual communications and media affordability definition given in the previous Section. The basic household needs (such as food, health, education 
and housing) at a basic level are to be decided from national policy data .Let " $A$ " by the communications and media affordability by household per year .

\subsection{Residual communications and media affordability NA}

It is thereafter proposed to track the residual communications and media affordability standard, in order to normalize it with the communications and media penetration rate, taking the maximum of the densities of communications access subscriptions and of the key digital media appliances (PC, CD readers). In many parts of the world, this penetration rate will end up being equal to the mobile penetration rate .Please note that this ratio is completely different to the ARPU notion determined by operators irrespectably from affordability considerations and income classes. Let " $\mathrm{d}$ " be the communications and media penetration rate per average household. Then the normalized communications and media affordability per subscription or appliance is NA $=A * d$ per year per household per subscription or appliance. It should be pointed out that this affordability measure, as other similar ones, assumes exclusive spending on communications and media from subscribing households once necessities are covered. Social research has shown that it is impossible to get better estimates in the event several non-necessities co-exist permanently or temporarily. If different locations need to be compared, NA needs to be normalized by a cost of living index.

Numerical case on averages:

US poverty level /household (2003): 18860 USD (Economic Policy Inst. [12])

Standard necessities others than communications and media (assuming for these a ratio comparable to elsewhere of $82 \%)(2003): 15500$ USD [16]

Average wireless penetration per household (2003):0,37 (FCC Data)

Average PC penetration per household (2003): $=0,2$ (NSTIA Data)

Average communications or appliance density per household $\mathrm{D}=\operatorname{Max}(0,37 ; 0,2)=0,37$

Average normalized communications and media affordability and value at risk from a household /year and per subscription or appliance: $\mathrm{NA}=(18860-15500) * 0,37=1243.20$ USD for subscribing households with this exclusive spending in USA (2003)

\subsection{Payments to communications and media suppliers NR}

After the normalized communications and media affordability NA has been determined as above, the key question is to compare it to the actual total payments NR by the household to $\mathrm{p}$ communications and media suppliers (excluding access terminal costs considered as an appliance investment). If the household accrues several usage subscriptions (post paid or prepaid) to communications and media, each accruing ARPU (i) average revenue per user per month:

$$
\mathrm{NR}=\operatorname{Sum}(\mathrm{ARPU}(\mathrm{i}) * 12, \mathrm{i}=1 \ldots \mathrm{p})+\text { MediaProducts }
$$

where MediaProducts is the annual sum of spot purchases of media not distributed over networks. It should be highlighted that as NR includes ARPU (i) and not communications traffic demands exceeding average (as may be the case with communications addiction).

Numerical case on averages:

US wireless ARPU per month (2003): ARPU (1) $=34$ USD (from CTIA data)

US fixed line ARPU per month (2003): ARPU (2) = 12 USD (from FCC data)

US CATV ARPU per month (2003): ARPU (3) = 21 USD (from Cable Labs data)

MediaProducts $(2003)=105$ USD

$\mathrm{NR}=905$ USD (2003) assuming all three communications media.

\subsection{Addiction vs. affordability: value at risk VaRCom}

The value at risk VaRCom for communications and media suppliers is: 


\section{VaRCom $=$ NA-NR}

which expresses the spending on communications and media not covered by the household's residual communications and media budget .If several alternative communications media choice exist for the household, like in the above US example with both wireless, fixed line and CATV, one has to choose the dominant combination for said income group.

Example : USA (2003) : VaRCom $=1243-905=338$ USD/year which shows that in the USA in 2003 , in average, the household's residual communications and media budget did cover the average spending at official poverty level, even when household has all three communications media, but assuming exclusive use on communications and media of non-necessities. But it is obvious that the margin is extremely thin especially in presence of other ancillary spending items.

Example Sweden (2006) : Assuming only wireless and Internet access technologies (and excluding CATV or SatTV), VaRCom $=13890-15600$ SEK $=(-1710)$ SEK (Konsumentverket [24]) which shows that in Sweden in 2006 , in average, the low income household's residual communications and media budget did not cover the average spending. This means that in average, such households had to reduce spending on other mandatory budget items (buying badly nutritious food, saving on health, relocation to cheaper public housing), or to use consumer credit, in order to maintain the communications and media spending.

VaRCom is a random variable, and full traditional value-at-risk analysis can be carried out if the underlying data are available. The statistical analysis of that Value of risk across a household group will very precisely characterize the risk inherent to communications and media addiction in view of affordability, and can be categorized by household size, income level, and location, at official poverty spending levels. When data are available it is further possible to compare the VaRCom value-at-risk profile, with the consumer credit and/or communications bills default curves [25].

The framework above and analysis method has been integrated into a single environment (including SPSS tools тM)) in collaboration with one risk analysis company and with a public regulated operator .Data have also been supplied by social administrations in one European and one Asian country.

\section{Affordability as a communications adoption accelerator}

In many vertical or geographical markets, it is obvious that affordability is an adoption factor for communications and media usage. But its role has been neglected in academic research in favor of technology diffusion or service attractiveness aspects. It is worth remembering that in many markets, however, adoption is driven mostly by affordability in that service diversity play only a lesser role than basic access to communications and media (for work, trading, job hunting, family relations, etc).

Let VaRCom (p, PopulationGroup) be the value at risk probability distribution within a given population with one income profile in a given market with homogeneous income, communications and media costs, and cost-of living characteristics. Let N (PopulationGroup) be the estimated size of that population, for which NR and NA are the respective residual income and affordability characteristics as explained above.

Under normal nominal conditions, the communications and media suppliers loose the average revenue NR from all households for which VaRCom (p, PopulationGroup) is negative, in that such households cannot under sustainable conditions afford to pay; the total lost revenue from that population group is thus:

LostRevenue $($ PopulationGroup $)=\mathrm{NR} * \mathrm{~N}($ PopulationGroup $) * \int$ VaRCom $(\mathrm{p}$, PopulationGroup $) \mathrm{dp} \mid($ VaRCom $<0)$

where NR obviously depends on tariffs applying to the PopulationGroup. The above formula allows, for given social and income characteristics, to determine not so much the lost revenue, but mostly its sensitivity to a rate change. If a tariff is reduced, NR will go down slightly but the non-linearity in the value-at-risk curve determined by the above methodology will often accelerate the reduction in lost potential revenue with a rapidly growing reduction in the negative VaRCom intervals.

Likewise, one can very readily extend the consequences of a living standard increase, in that the increase in the communications and media affordability NA translates into a shift in the value at risk curve with an immediate revaluation of the LostRevenue. 
Finally, communications and media addiction situations, although mostly individual, can be treated as extreme cases in the analysis above which thus serves as a unifying framework.

This calculation method has been applied to rural communities in China and India in view of policy analysis for sustainable communications and media adoption [26, 27].

\section{ICT and policy implications}

From the above analysis, as well as from the implementations of the analysis methodology on a number of cases for which data or good estimates were made available, the following policy recommendations can be made:

1. As communications and media demand and fashion patterns are highly volatile, the residual communications and media affordability should be tracked over time and evaluated against the household size; tracking ARPU is not enough!

2. Eligibility and payment standards for communications and media subsidies: in an information based society, one wonders why, when necessary, housing subsidies (like US rent subsidy and equivalents) [28] are not extended to some basic communications demand to help beneficiaries in their social and workforce insertion; the residual communications and media affordability determination could help here as well.

3. The flexibility offered by individual communications tariffs [26] over fixed bundles would allow some households to represent a lesser risk level to suppliers and to themselves, provided they can specify a usage ceiling meeting real needs rather than service addiction

4. There is an opportunity to shape some simple regulations taking into account the fact that many younger people especially have no idea of the real costs of what they buy over time .It would be simple to implement a messaging service by the operators back to the users when the consumption pattern over time is likely to exceed the residual communications and media affordability, based on a declared income. This could be a partial measure inside the planned EU regulations for financial education to consumers, such as www.dolceta.eu and the "Agenda Europe"

5. Finally, the analysis also proves very useful in determining the adoption potential for wireless and broadband services in lesser developed countries, or amongst less affluent parts of the population in such countries. A systematic estimation of a given VarRCom fractile across populations for which the income and income structures are known, allow to determine realistic entry tariffs in the determination of NR as done e.g. in India [27]

Research in this field is obviously subject to access to micro-level data like such as [3, 29]. It has been especially encouraging to see how well wireless adoption trends and timing (incremental adoption in saturated markets amongst poor households, and new adoption in emerging countries) could be explained by the analysis environment applied to relevant data. Later reports are going to focus on the impact on wireless and Internet adoption timing.

\section{References}

[1] Jenkins, R., 2004, Social identity, Cambridge, UK: Routeledge

[2] Elliott, A., and Lemert, C., 2005, The new individualism, Cambridge, UK: Routeledge

[3] Vatne, B.H., 2006 , Hvor store ökonomiske marginer har husholdningerne ? En analyse på mikrodata 1987-2004, Penger og Kreditt 3/2006, Oslo : Norges Bank

[4] Observatoire national de la pauvreté et de l'exclusion sociale, 2006, Paris : Documentation française www.ladocumentationsociale.fr

[5] Feins, J. and Lane, T.S., 1981, How much for housing?, Cambridge, MA: ABT Assoc.

[6] Yip, N.M., 1995, Housing affordability in England, DPhil thesis, Univ. of York, Dept. of social policy and social work

[7] Hulchanski, J.D., 1995, The concept of housing affordability, Housing studies, 10, 4, 471-491 
[8] Wilcox, S., 1999, The vexed question of affordability, Edinburgh: Scottish Homes

[9] Lerman, D.L., and Reeder, W.J., 1987, The affordability of adequate housing, American Real estate and urban economics association J., 15, 4, 389-404

[10] Linneman, P.D. and Megbolugbe, I.F., 1992, Housing affordability: myth or reality, Urban studies, 28, 3/4, 369-392

[11] Kempson, E., 1993, Household budgets and housing costs, London: Policy studies Institute

[12] Economic Policy Institute, 2005, EPI Issue guide: poverty and family budgets: Guide to creating a basic family budget, Washington DC: EPI, www.epinet.org/content.cfm/issueguides poverty instructions

[13] Bernstein; Brocht, C.and Spade-Aguilar, 2000, How much is enough? Basic family budgets for working families, Washington DC: Economics Policy Institute

[14] Expert committee on family budget revisions, 1980, New American family budget standards, Washington, D.C.: US Government printing office

[15] Pearce, D, and Brooks, J., 2003, The self sufficiency standards for Massachusetts, Prepared for the Women's educational and industrial union, Washington DC : WEIU www.weiu.org/pdf files/MA full report final.pdf

[16] Allegretto, S., 2005, Basic family budgets, Economic Policy Institute briefing paper no 165, Washington DC: EPI , www.epinet.org/briefingpapers/165/bp165.pdf

[17] CASA ( Center for alternative samfundsanalyse), 2003, Sociale ydelser set $i$ et fattigdomsperspektiv, Rådets småskriftserie 1/2003,Appendix 3, Copenhagen : Rådet for socialt udsatte

[18] Secours catholique, 2007, Rapport statistique 2007 sur la géographie de la pauvreté, Paris : Secours catholique www.secours-catholique.org

[19] Ling, R.R. and Perdersen, P.E. (Eds), 2005, Mobile Communications: Re-Negotiation of the Social Sphere (Computer Supported Cooperative Work), London: Springer Verlag

[20] Intrium Justitia, 2007, Fair Pay, no 2/07, Stockholm: Intrium Justitia

[21] Teleclik, 2006, Daily bulletin on Internet and Blackberry addiction, Menlo Park: Stanford University, www.teleclick.ca/2006/10/stanford-university-study-explores-internet-addiction-statistics

[22] BuddeCom, 2005, Mobile phone addiction in Korea, www.budde.com.au/Reports/Contents/South-Korea-MobileCommunications-Market-Overview-2632.html

[23] Hancock, K.E., 1993: Can't pay? Won't pay, The economic principles of affordability, Urban studies, 30, 1, 127-145

[24] Konsumentverket , 2005, Consumer statistics, Stockholm www.kkv.se/upload/Filer/Trycksaker/Rapporter/rap 2005-1.pdf

[25] Johansson, P. \& Persson, A., 2006, Swedish households' indebtness and ability to pay: a household study, Penning och valutapolitik 3/2006, Stockholm: Sveriges Riksbank

[26] Individual telecommunications tariffs in Chinese communities

[27] India: a case of fragile wireless service and technology adoption?

[28] Stone, M.E., 1993, Shelter poverty: new ideas on housing affordability, Philadelphia: Temple University Press

[29] Bradshaw. (Ed), 1993, Budget standards for the United Kingdom, Aldershot, England: Avebury/Ashgate

[30] Citro, C. and Robert, M. (Eds), 1995, Measuring poverty: a new approach, Washington, DC: National Academy Press 


\section{Publications in the Report Series Research ${ }^{*}$ in Management}

\section{ERIM Research Program: "Business Processes, Logistics and Information Systems"}

2008

An Evolutionary Framework for Determining Heterogeneous Strategies in Multi-Agent Marketplaces

Alexander Babanov, Wolfgang Ketter and Maria Gini

ERS-2008-002-LIS

http://hdl.handle.net/1765/10972

Choosing between Auctions and Negotiations in Online B2B Markets for IT Services: The Effect of Prior Relationships and Performance

Uladzimir Radkevitch, Eric van Heck and Otto Koppius

ERS-2008-004-LIS

http://hdl.handle.net/1765/11288

Key Issues in Expansion of End-User Mobile Communication in China

Sunanda Sangwan, Guan Chong and Louis-Francois Pau

ERS-2008-011-LIS

http://hdl.handle.net/1765/11762

Some Comments on the Question Whether Co-Occurrence Data Should Be Normalized

Ludo Waltman and Nees Jan van Eck

ERS-2008-014-LIS

http://hdl.handle.net/1765/11810

Bibliometric Mapping of the Computational Intelligence Field

Nees Jan van Eck and Ludo Waltman

ERS-2008-015-LIS

http://hdl.handle.net/1765/11811

Demand Management Opportunities in E-fulfillment: What Internet Retailers Can Learn from Revenue Management Niels Agatz, Ann Campbell, Moritz Fleischmann, Jo van Nunen and Martin Savelsbergh ERS-2008-021-LIS

http://hdl.handle.net/1765/12244

Time Slot Management in Attended Home Delivery

Niels Agatz, Ann Campbell, Moritz Fleischmann and Martin Savelsbergh

ERS-2008-022-LIS

http://hdl.handle.net/1765/12245

Mobile Service Affordability for the Needy, Addiction, and ICT Policy Implications

L-F Pau

ERS-2008-023-LIS

http://hdl.handle.net/1765/12246

\footnotetext{
* A complete overview of the ERIM Report Series Research in Management: https://ep.eur.nl/handle/1765/1

ERIM Research Programs:

LIS Business Processes, Logistics and Information Systems

ORG Organizing for Performance

MKT Marketing

F\&A Finance and Accounting

STR Strategy and Entrepreneurship
} 